Proceedings of the

International Geometry Center

Vol. 12 , no. 1 (2019) pp. 41-55

\title{
Three spectra problem for Stieltjes string equation and Neumann conditions
}

\author{
Anastasia Dudko, Vyacheslav Pivovarchik
}

\begin{abstract}
Spectral problems are considered which appear in description of small transversal vibrations of Stieltjes strings. It is shown that the eigenvalues of the Neumann-Neumann problem, i.e. the problem with the Neumann conditions at both ends of the string interlace with the union of the spectra of the Neumann-Dirichlet problems, i.e. problems with the Neumann condition at one end and Dirichlet condition at the other end on two parts of the string. It is shown that the spectrum of Neumann-Neumann problem on the whole string, the spectrum of Neumann-Dirichlet problem on the left part of the string, all but one eigenvalues of the Neumann-Dirichlet problem on the right part of the string and total masses of the parts uniquely determine the masses and the intervals between them.
\end{abstract}

Анотація. Скінченновимірні спектральні задачі виникають у механіці при описі малих поперечних коливань, так званих, стільтьєсівських струн та повздовжних коливань точкових мас, з'єднаних пружинами. Вони також виникають у теорії синтезу електричних ланцюгів.

Обернені задачі полягають у відновленні параметрів системи, виходячи зі спектрів їі коливань. У роботах М. Г. Крейна була повністю розв'язана обернена задача за двома спектрами, тобто за спектром задачі з умовами Діріхле на обох кінцях інтервалу та спектром задачі з умовою Діріхле на лівому кінці та умовою Ноймана на правому кінці.

Замість двох спектрів задач на всьому інтервалі можна взяти спектр задачі на всьому інтервалі та спектри задач на двох частинах цього інтервалу.

В нашій статті ми розглядаємо спектральну задачу, породжену рекурентними співвідношеннями стільтьєсівської струни з умовами Ноймана на обох кінцях (задача Ноймана-Ноймана) разом із задачами на частинах інтервалу з умовами Ноймана на лівому кінці та Діріхле на правому кінці (задача Ноймана-Діріхле). Ми показали, що власні значення задачі Ноймана-Ноймана на всьому інтервалі чергуються з елементами об'єднання спектрів задач Ноймана-Діріхле на частинах інтервалу.

Відповідна обернена задача полягає у знаходженні параметрів стільтьєсівської струни (величин точкових мас та інтервалів між ними), виходячи із загальних мас частин струни, спектрів задач Ноймана-Ноймана на всій струні та Ноймана-Діріхле на частинах струни. 
Для такої задачі ми довели, що спектр задачі Ноймана-Ноймана на всій струні, спектр задачі Ноймана-Діріхле на лівій частині струни, всі, крім одного, власні значення задачі Ноймана-Діріхле на правій частині струни та загальні маси обох частин струни однозначно визначають величини всіх точкових мас та інтервали між ними.

\section{INTRODUCTION}

Finite dimensional spectral problems have physical interpretations in mechanics where they appear in description of transverse vibrations of the so-called Stieltjes strings (see [12] and [6, Addition II]), of longitudinal vibrations of point masses connected by springs [13]. They have also an interpretation in the synthesis of electric circuits $[10,5,4]$. Inverse problems lie in recovering the parameters of the system using the spectrum or spectra of its vibrations. In [6] the inverse problem for a single Stieltjes string was solved completely. In particular, it was shown that in order to recover parameters of a string it is necessary to know two spectra of boundary value problems with different boundary conditions. Also in [6] conditions were found necessary and sufficient for two sequences of numbers to be the spectra of such problems.

Generalizations for the case of damped Stieltjes strings were obtained in $[17,1]$, and for trees of Stieltjes strings in [7, 8, 9, 15, 2, 16], see also [14].

In [3] a three spectra inverse problem was considered: given the spectra of a Dirichlet-Dirichlet problem on a whole string and Dirichlet-Dirichlet problems on two parts of the string together with lengths of the parts, find the masses and the subintervals between them. In the present paper we consider an analogue of this result for the case of a Neumann-Neumann problem on the whole string and the Neumann-Dirichlet problems on two parts of the string.

In Section 2 we consider the direct three spectra problem. We show that the eigenvalues of a Neumann-Neumann problem interlace in a not strict sense with the union of the spectra of Neumann-Dirichlet problems on the parts of the string and with the union of the spectra of Neumann-Neumann problems on the parts of the string.

In Section 3 we solve the corresponding inverse three spectra problem: given the spectrum of a Neumann-Neumann problem on a whole string, the spectrum of a Neumann-Dirichlet problem on the left part of the string, all but one eigenvalues of the Neumann-Dirichlet problem on the right part of the string and the total masses of the parts of the string, find all the point masses and all the intervals between them except for the intervals neighboring the ends of the string. It turns out that due to the fact that the lowest eigenvalue of any Neumann-Neumann problem is 0, a three spectra 
inverse problem appears to be overdetermined if all three spectra are given. Therefore, we use the Neumann-Neumann spectrum of the problem on the whole interval, a Neumann-Dirichlet problem on the left part of the string and all but one eigenvalues of a Neumann-Dirichlet problem on the right part of the string. Also we give conditions on three sequences of numbers necessary to be the spectrum of the Neumann-Neumann problem on a whole string (the first sequence), the spectrum of the Neumann-Dirichlet problem on a part of the string (the second sequence), and a part of the spectrum of the Neumann-Dirichlet problem on the second part of the string (the third sequence).

\section{Direct Spectral Problem}

We consider a Stieltjes string (an elastic massless thread bearing a finite number of point masses). The string consists of two parts, which are joined at one end while the other end is free to move in the direction orthogonal to the equilibrium position of the string. The joining point is free of mass. We measure distances from the free ends. Starting indexing from the free ends, $n_{j}$ masses $m_{k}^{(j)}>0, k=1, \ldots, n_{j}$, are positioned on the $j$-th part, $j=1,2$, which divide the $j$-th part into $n_{j}+1 \quad\left(n_{j} \geq 1\right)$ subintervals denoted by $l_{k}^{(j)}>0 \quad\left(k=0, \ldots, n_{j}\right)$ again starting indexing from the free ends.

In particular, $l_{0}^{(j)}$ is the distance on the $j$-th part between the free endpoint and $m_{1}^{(j)}, l_{k}^{(j)}$ for $\left(k=1, \ldots, n_{j}-1\right)$ is the distance between $m_{k}^{(j)}$ and $m_{k+1}^{(j)}$, and $l_{n_{j}}^{(j)}$ is the distance on the $j$-th thread between the joined endpoint $P$ and $m_{n_{j}}^{(j)}$.

The tension of the thread is assumed to be equal to 1 . The transversal displacement of the point mass $m_{k}^{(j)}$ at the time $t$ is denoted by $v_{k}^{(j)}$. For the convenience, we denote by $v_{0}^{(j)}$ the transversal displacement of the free endpoints and by $v_{n_{j}+1}^{(j)}(t)$ the transversal displacement at the joint endpoints, see Figure 2.1.

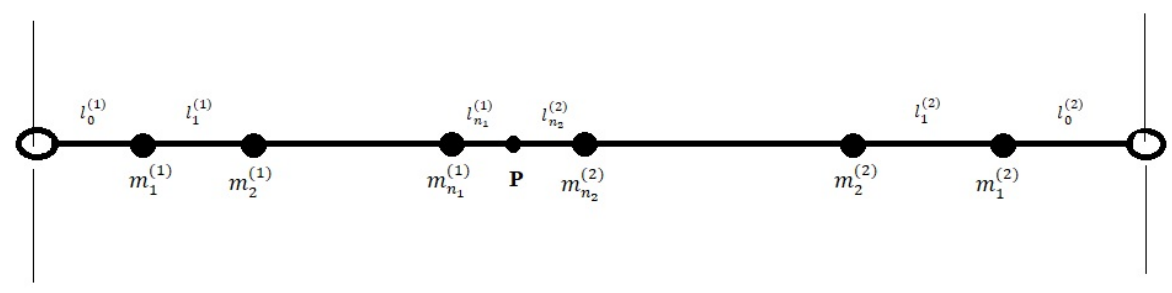

FiguRE 2.1. 
Total masses of the strings are denoted by $m_{j}$ :

$$
m_{j}=\sum_{k=1}^{n_{j}} m_{k}^{(j)}
$$

Newton's law gives the following equations of motion for the masses:

$$
\frac{v_{k}^{(j)}(t)-v_{k+1}^{(j)}(t)}{l_{k}^{(j)}}+\frac{v_{k}^{(j)}(t)-v_{k-1}^{(j)}(t)}{l_{k-1}^{(j)}}+m_{k}^{(j)} v_{k}^{(j)^{\prime \prime}}(t)=0,
$$

$k=1, \ldots, n_{j}, j=1,2$. The joined ends give rise to

$$
v_{n_{1}+1}^{(1)}(t)=v_{n_{2}+1}^{(2)}(t)
$$

and the balance of forces at $P$ leads to

$$
\sum_{j=1}^{2} \frac{v_{n_{j}}^{(j)}(t)-v_{n_{j}+1}^{(j)}(t)}{l_{n_{j}}^{(j)}}=0
$$

At the free ends we have

$$
v_{0}^{(j)}(t)=v_{1}^{(j)}(t), \quad j=1,2,
$$

which means that the ends are free to move in the direction orthogonal to the equilibrium position of the string. Substituting $v_{k}^{(j)}(t)=u_{k}^{(j)} e^{i \lambda t}$ and changing the spectral parameter for $z=\lambda^{2}$ we obtain the following recurrences for the amplitudes $u_{k}^{(j)},\left(k=1, \ldots, n_{j}, j=1,2\right)$, of vibrations:

$$
\begin{gathered}
\frac{u_{k}^{(j)}-u_{k+1}^{(j)}}{l_{k}^{(j)}}+\frac{u_{k}^{(j)}-u_{k-1}^{(j)}}{l_{k-1}^{(j)}}-m_{k}^{(j)} z u_{k}^{(j)}=0, \\
u_{n_{1}+1}^{(1)}=u_{n_{2}+1}^{(2)}, \\
\sum_{j=1}^{2} \frac{u_{n_{j}}^{(j)}-u_{n_{j}+1}^{(j)}}{l_{n_{j}}^{(j)}}=0, \\
u_{0}^{(j)}=u_{1}^{(j)}, \quad j=1,2 .
\end{gathered}
$$

Following [6] we look for the solution to (2.2)-(2.5) in the form:

$$
u_{k}^{(j)}=Q_{2 k-2}^{(j)}(z) u_{1}^{(j)} \quad\left(k=1, \ldots, n_{j}, \quad j=1,2\right),
$$

where $Q_{2 k-2}^{(j)}(z)$ is a polynomial of degree $k-1$, which are the solutions of (2.2) and (2.5). 
We introduce the polynomials of odd index:

$$
Q_{2 k-1}^{(j)}(z)=\frac{Q_{2 k}^{(j)}(z)-Q_{2 k-2}^{(j)}(z)}{l_{k}^{(j)}}
$$

According to (2.2) and (2.7) the polynomials $Q_{k}^{(j)}$ satisfy the recurrences

$$
\begin{gathered}
Q_{2 k-1}^{(j)}(z)=-z m_{k}^{(j)} Q_{2 k-2}^{(j)}(z)+Q_{2 k-3}^{(j)}(z), \\
Q_{2 k}^{(j)}(z)=l_{k}^{(j)} Q_{2 k-1}^{(j)}(z)+Q_{2 k-2}^{(j)}(z),
\end{gathered}
$$

$k=1, \ldots, n_{j}, j=1,2$, and the initial conditions

$$
Q_{-1}^{(j)}(z)=0, \quad Q_{0}^{(j)}(z)=1 .
$$

Substituting (2.6) into (2.3) and (2.4) we obtain:

$$
\begin{gathered}
Q_{2 n_{1}}^{(1)}(z) u_{1}^{(1)}=Q_{2 n_{2}}^{(2)}(z) u_{1}^{(2)}, \\
\sum_{j=1}^{2} Q_{2 n_{j}-1}^{(j)}(z) u_{1}^{(j)}=0 .
\end{gathered}
$$

The spectrum of problem (2.2)-(2.5) coincides with the set of zeros of the determinant of system $(2.8),(2.9)$, i.e. of the polynomial

$$
\phi(z)=Q_{2 n_{1}-1}^{(1)}(z) Q_{2 n_{2}}^{(2)}(z)+Q_{2 n_{1}}^{(1)}(z) Q_{2 n_{2}-1}^{(2)}(z) .
$$

It is clear that $Q_{2 n_{j}}^{(j)}(z)$ is the characteristic polynomial of a NeumannDirichlet problem on $j$-th string:

$$
\begin{gathered}
\frac{u_{k}^{(j)}-u_{k+1}^{(j)}}{l_{k}^{(j)}}+\frac{u_{k}^{(j)}-u_{k-1}^{(j)}}{l_{k-1}^{(j)}}-m_{k}^{(j)} z u_{k}^{(j)}=0 \\
u_{0}^{(j)}=u_{1}^{(j)}, \\
u_{n_{j}+1}^{(j)}=0
\end{gathered}
$$

$k=1, \ldots, n_{j}$, while $Q_{2 n_{j}-1}^{(j)}(z)$ is the characteristic polynomial of the Neumann-Neumann problem on the $j$-th string:

$$
\begin{gathered}
\frac{u_{k}^{(j)}-u_{k+1}^{(j)}}{l_{k}^{(j)}}+\frac{u_{k}^{(j)}-u_{k-1}^{(j)}}{l_{k-1}^{(j)}}-m_{k}^{(j)} z u_{k}^{(j)}=0 \quad\left(k=1, \ldots, n_{j}\right) \\
u_{0}^{(j)}=u_{1}^{(j)} \\
u_{n_{j}+1}^{(j)}=u_{n_{j}}^{(j)}
\end{gathered}
$$


According to $\left[6\right.$, Appendix II, equation (28)] the ratio $\frac{Q_{2 n_{j}}^{(j)}(z)}{Q_{2 n_{j}-1}^{(j)}(z)}$ can be expanded into the following continued fraction:

$$
\frac{Q_{2 n_{j}}^{(j)}(z)}{Q_{2 n_{j}-1}^{(j)}(z)}=l_{n_{j}}^{(j)}+\frac{1}{-m_{n_{j}}^{(j)} z+\frac{1}{l_{n_{j}-1}^{(j)}+\frac{1}{-m_{n_{j}-1}^{(j)} z+\cdots+\frac{1}{l_{1}^{(j)}+\frac{1}{-m_{1}^{(j)} z}}}},}
$$

and with account of (2.1) we obtain

$$
\lim _{z \rightarrow 0} \frac{Q_{2 n_{j}-1}^{(j)}(z)}{z Q_{2 n_{j}}^{(j)}(z)}=-m_{j}
$$

Definition 2.1. (see e.g. [14, Definition 5.1.20]). A function $\omega(z)$ is said to be Nevanlinna (or $R$-function in terms of [11]), if:

1) the function $\omega(z)$ is analytic in the half-planes $\operatorname{Im} z>0$ and $\operatorname{Im} z<0$;

2) $\omega(\bar{z})=\overline{\omega(z)}$;

3) $\operatorname{Im} z \operatorname{Im} \omega(z) \geq 0$ for $\operatorname{Im} z \neq 0$.

Definition 2.2. (see [11] or [14, Definition 5.1.24]). A Nevanlinna function $\omega(z)$ is said to be $S$-function, if $\omega(z)>0$ for $z<0$.

Theorem 2.3. After cancellation of common factors (if any) in the numerator and the denominator the function

$$
\frac{\prod_{j=1}^{2} Q_{2 n_{j}}^{(j)}(z)}{\phi(z)}
$$

becomes an S-function.

Proof. Using (2.10) we arrive at

$$
\frac{\prod_{j=1}^{2} Q_{2 n_{j}}^{(j)}(z)}{\phi(z)}=\left(\sum_{j=1}^{2} \frac{Q_{2 n_{j}-1}^{(j)}(z)}{Q_{2 n_{j}}^{(j)}(z)}\right)^{-1} .
$$

Since $\frac{Q_{2 n_{j}}^{(j)}(z)}{Q_{2 n_{j}-1}^{(j)}(z)}$ is a Nevanlinna function, we conclude, see [14, Lemma 2.4.5], that $-\frac{Q_{2 n_{j}-1}^{(j)}(z)}{Q_{2 n_{j}}^{(j)}(z)}$ is a Nevanlinna function too as well as $\left(\sum_{j=1}^{2} \frac{Q_{2 n_{j}-1}^{(j)}(z)}{Q_{2 n_{j}}^{(j)}(z)}\right)^{-1}$. 
Since the $S$-function $\frac{Q_{2 n_{j}}^{(j)}(z)}{Q_{2 n_{j}-1}^{(j)}(z)}$ is positive for all $z \in(-\infty, 0)$, it follows that $\left(\sum_{j=1}^{2} \frac{Q_{2 n_{j}-1}^{(j)}(z)}{Q_{2 n_{j}}^{(j)}(z)}\right)^{-1}$ is also positive for $z \in(-\infty, 0)$.

Let $n=\sum_{j=1}^{2} n_{j}$ and $\left\{\mu_{k}\right\}_{k=1}^{n}\left(\mu_{k} \geq \mu_{k^{\prime}}\right.$ for $\left.k>k^{\prime}\right)$ be the eigenvalues of problem (2.2)-(2.5).

Now let us consider the spectral problem which describes the case where the point $P$ is clamped. Then instead of equations (2.2)-(2.5) we have

$$
\begin{gathered}
\frac{u_{k}^{(j)}-u_{k+1}^{(j)}}{l_{k}^{(j)}}+\frac{u_{k}^{(j)}-u_{k-1}^{(j)}}{l_{k-1}^{(j)}}-m_{k}^{(j)} z u_{k}^{(j)}=0 \\
u_{n_{1}+1}^{(1)}=u_{n_{2}+1}^{(2)}=0 \\
u_{0}^{(j)}=u_{1}^{(j)}
\end{gathered}
$$

for $k=1, \ldots, n_{j}$ and $j=1,2$.

Denote by $\left\{\xi_{k}\right\}_{k=1}^{n} \quad\left(\xi_{k} \leq \xi_{k+1}\right)$ the spectrum of problem (2.18)-(2.20) and by $\left\{\nu_{k}^{(j)}\right\}_{k=1}^{n_{j}},\left(\nu_{k}^{(j)}<\nu_{k+1}^{(j)}\right)$ the spectrum of Newmann-Dirichlet problem (2.11)-(2.13) on $j$-th string. The spectrum $\left\{\xi_{k}\right\}_{k=1}^{n}$ is the union of the spectra of problems (2.11)-(2.13), i.e. $\left\{\xi_{k}\right\}_{k=1}^{n}=\bigcup_{j=1}^{2}\left\{\nu_{k}^{(j)}\right\}_{k=1}^{n_{j}}$.

Theorem 2.4. The sequences $\left\{\mu_{k}\right\}_{k=1}^{n}$ and $\left\{\xi_{k}\right\}_{k=1}^{n}$ satisfy the following conditions:

1) $0=\mu_{1}<\xi_{1} \leq \mu_{2} \leq \cdots \leq \xi_{n}$;

2) $\mu_{k}=\xi_{k-1}$ if and only if $\mu_{k}=\xi_{k},(k=2, \ldots, n)$;

3) the multiplicity of each $\xi_{k}$ does not exceed 2.

Proof. By Theorem 2.3 the rational function

$$
\frac{\prod_{j=1}^{2} Q_{2 n_{j}}^{(j)}(z)}{\phi(z)}
$$

is an $S$-function (after cancellation of common factors in the numerator and the denominator, if any) and thus the zeros of this rational function interlace with its poles:

$$
0 \leq \mu_{1} \leq \xi_{1} \leq \mu_{2} \leq \ldots \leq \xi_{n}
$$


Let $\xi_{k}=\mu_{k}$ and $\xi_{k}=\nu_{p}^{(1)}$ for some $k$ and $p$, then (2.10) implies

$$
Q_{2 n_{1}-1}^{(1)}\left(\nu_{p}^{(1)}\right) Q_{2 n_{2}}^{(2)}\left(\nu_{p}^{(1)}\right)+Q_{2 n_{1}}^{(1)}\left(\nu_{p}^{(1)}\right) Q_{2 n_{2}-1}^{(2)}\left(\nu_{p}^{(1)}\right)=0 .
$$

Since $\nu_{p}^{(1)}$ is a zero of the polynomial $Q_{2 n_{1}}^{(1)}(z)$ we have $Q_{2 n_{j}-1}^{(j)}\left(\nu_{p}^{(j)}\right) \neq 0$. Then due to (2.21) we obtain

$$
Q_{2 n_{1}-1}^{(1)}\left(\nu_{p}^{(j)}\right) Q_{2 n_{2}}^{(2)}\left(\nu_{p}^{(1)}\right)=0
$$

and, consequently,

$$
Q_{2 n_{2}}^{(2)}\left(\nu_{p}^{(1)}\right)=0
$$

Thus, $\xi_{k-1}=\xi_{k}$ and $\xi_{k-1}=\mu_{k}=\xi_{k}$ and statement 2) is proved.

Statement 2) implies $\mu_{1}<\xi_{1}$. Since $Q_{2 n_{j}-1}^{(j)}(0)=0$ for $j=1$ and $j=2$ we see that due to $(2.10) \phi(0)=0$, and therefore $\mu_{1}=0$ and statement 1 ) is proved.

The multiplicity of the zeros of $\prod_{j=1}^{2} Q_{2 n_{j}}^{(j)}(z)$ can not exceed 2 because each factor in the product has only simple zeros.

Theorem 2.5. After cancellation of common factors in the numerator and denominator the rational function

$$
\frac{\phi(z)}{\prod_{j=1}^{2} Q_{2 n_{j}-1}^{(j)}(z)}
$$

becomes an S-function.

Proof. Using (2.10) we obtain

$$
\frac{\phi(z)}{\prod_{j=1}^{2} Q_{2 n_{j}-1}^{(j)}(z)}=\frac{Q_{2 n_{1}}^{(1)}(z)}{Q_{2 n_{1}-1}^{(1)}(z)}+\frac{Q_{2 n_{2}}^{(2)}(z)}{Q_{2 n_{2}-1}^{(2)}(z)}
$$

Since $\frac{Q_{2 n_{j}}^{(j)}(z)}{Q_{2 n_{j}-1}^{(j)}(z)}(j=1,2)$ are $S$-functions we conclude that their sum is an $S$-function too, see [14, Lemma 2.5.4].

Denote by $\left\{\chi_{k}^{(j)}\right\}_{k=1}^{n_{j}}, 0=\chi_{1}^{(j)}<\chi_{2}^{(j)}<\cdots<\chi_{n_{j}}^{(j)}$, the zeros of the polynomial $Q_{2 n_{j}-1}^{(j)}(z)$ and let

$$
\left\{\tau_{k}\right\}_{k=1}^{n}=\bigcup_{j=1}^{2}\left\{\chi_{k}^{(j)}\right\}_{k=1}^{n_{j}}
$$


Theorem 2.6. The sequence $\left\{\tau_{k}\right\}_{k=1}^{n}$ interlaces with $\left\{\mu_{k}\right\}_{k=1}^{n}$ as follows:

1) $0=\tau_{1}=\mu_{1}=\tau_{2}<\mu_{2}<\tau_{3} \leq \mu_{3} \leq \tau_{4} \leq \cdots<\mu_{n}$;

2) $\mu_{k}=\tau_{k},(k=3, \ldots, n-1)$, if and only if $\mu_{k}=\tau_{k+1}$;

3) the multiplicity of $\tau_{k}$ does not exceed 2.

Proof. Since by Theorem 2.5

$$
\frac{\phi(z)}{\prod_{j=1}^{2} Q_{2 n_{j}-1}^{(j)}(z)}
$$

is an $S$-function (after cancellation of common factors in the numerator and the denominator, if any) and thus the zeros of this rational function interlace with its poles:

$$
\tau_{1} \leq \mu_{1} \leq \tau_{2} \leq \mu_{2} \leq \tau_{3} \leq \mu_{3} \leq \tau_{4} \leq \cdots \leq \mu_{n} .
$$

Let $\mu_{k}=\tau_{k}=\chi_{p}^{(1)}$ then

$$
Q_{2 n_{1}-1}^{(1)}\left(\chi_{p}^{(1)}\right) Q_{2 n_{2}}^{(2)}\left(\chi_{p}^{(1)}\right)+Q_{2 n_{1}}^{(1)}\left(\chi_{p}^{(1)}\right) Q_{2 n_{2}-1}^{(2)}\left(\chi_{p}^{(1)}\right)=0 .
$$

implies

$$
Q_{2 n_{1}}^{(1)}\left(\chi_{p}^{(1)}\right) Q_{2 n_{2}-1}^{(2)}\left(\chi_{p}^{(1)}\right)=0 .
$$

Since $Q_{2 n_{1}-1}^{(1)}\left(\chi_{p}^{(1)}\right)=0$ implies $Q_{2 n_{1}}^{(1)}\left(\chi_{p}^{(1)}\right) \neq 0$, we have $Q_{2 n_{1}}^{(1)}\left(\chi_{r}^{(2)}\right)=0$. Statement 2) is proved.

Since $\chi_{1}^{(1)}=\chi_{1}^{(2)}=0$ we have $\tau_{1}=\tau_{2}=\mu_{1}=0$. This together with Statement 2) implies Statement 1).

Statement 3 ) follows from simplicity of the eigenvalues of each of problems (2.11), (2.14), (2.15) with $j=1$ and $j=2$.

\section{INVERSE PROBLEM}

In this section we consider the inverse problem of recovering the sets

$$
\left\{m_{k}^{(j)}\right\}_{k=1}^{n_{j}}, \quad\left\{l_{k}^{(j)}\right\}_{k=1}^{n_{j}}, \quad j=1,2,
$$

using the spectrum $\left\{\mu_{k}\right\}_{k=1}^{n}$, all but one elements of

$$
\left\{\xi_{k}\right\}_{k=1}^{n}=\bigcup_{j=1}^{2}\left\{\nu_{k}^{(j)}\right\}_{k=1}^{n_{j}}
$$

and the total masses $m_{j}$ of the parts of the string. Here $n=\sum_{j=1}^{2} n_{j}$. 
Theorem 3.1. Let the total masses $m_{j}>0, j=1,2$, be given. Let also $\left\{\mu_{k}\right\}_{k=1}^{n}$ be the spectrum of problem (2.2)-(2.5), $\left\{\nu_{k}^{(1)}\right\}_{k=1}^{n_{1}}$ be the spectrum of problem (2.11)-(2.13) with $j=1$, and $\left\{\nu_{k}^{(2)}\right\}_{k=1}^{n_{2}-1}$ be a sequence of eigenvalues (a part of spectrum) of problem (2.11)-(2.13) with $j=2$ such that

$$
0=\mu_{1}<\xi_{1}<\mu_{2}<\xi_{2}<\cdots<\xi_{n-1}<\mu_{n},
$$

where $\left\{\xi_{k}\right\}_{k=1}^{n-1}=\left\{\nu_{k}^{(1)}\right\}_{k=1}^{n_{1}} \bigcup\left\{\nu_{k}^{(2)}\right\}_{k=1}^{n_{2}-1}$.

Then these data uniquely determine the masses $\left\{m_{k}^{(j)}\right\}_{k=1}^{n_{j}}, \quad(j=1,2)$ and the intervals $\left\{l_{k}^{(j)}\right\}_{k=1}^{n_{j}}, j=1,2$.

Proof. Let us construct the following polynomials:

$$
\begin{aligned}
& R_{0}(z)=\left(m_{1}+m_{2}\right) \prod_{k=2}^{n}\left(1-\frac{z}{\mu_{k}}\right), \\
& R_{1}(z)=\prod_{k=1}^{n_{1}}\left(1-\frac{z}{\nu_{k}^{(1)}}\right), \\
& R_{2}(z)=\prod_{k=1}^{n_{2}-1}\left(1-\frac{z}{\nu_{k}^{(2)}}\right) .
\end{aligned}
$$

We consider the following functional equation

$$
R_{0}(z)=m_{2} R_{1}(z) \tilde{X}_{2}(z)+m_{1} R_{2}(z) \tilde{X}_{1}(z)
$$

under the conditions $\tilde{X}_{1}(0)=\tilde{X}_{2}(0)=1$. Substituting $z=\nu_{k}^{(1)}$ into equation (3.5), and taking into account (3.2)-(3.4) (notice that (3.1) and (3.4) imply $R_{2}\left(\nu_{k}^{(1)}\right) \neq 0$ ), we obtain

$$
\tilde{X}_{1}\left(\nu_{p}^{(1)}\right)=\frac{\left(m_{1}+m_{2}\right) \prod_{k=2}^{n}\left(1-\frac{\nu_{p}^{(1)}}{\mu_{k}}\right)}{m_{1} \prod_{k=1}^{n_{2}-1}\left(1-\frac{\nu_{p}^{(1)}}{\nu_{k}^{(2)}}\right)} .
$$

Denote $\nu_{0}^{(1)}=0$ and set

$$
\tilde{X}_{1}\left(\nu_{0}^{(1)}\right)=1 .
$$

Let us construct the following Lagrange interpolating polynomial

$$
\tilde{X}_{1}(z)=\sum_{p=0}^{n_{1}} \tilde{X}_{1}\left(\nu_{p}^{(1)}\right) \prod_{i \neq p, i=0}^{n_{1}} \frac{z-\nu_{i}^{(1)}}{\nu_{p}^{(1)}-\nu_{i}^{(1)}} .
$$


Denote by $\left\{\chi_{k}\right\}_{k=2}^{n_{1}+1}$ the zeros of the polynomial $\tilde{X}_{1}$. Evidently,

$$
\tilde{X}_{1}\left(\nu_{p}^{(1)}\right)=\frac{R_{0}\left(\nu_{p}^{(1)}\right)}{m_{1} R_{2}\left(\nu_{p}^{(1)}\right)}=\frac{R_{0}\left(\nu_{p}^{(1)}\right)}{m_{1}}\left(\frac{\left.\frac{d}{d z}\left(R_{1}(z) R_{2}(z)\right)\right|_{z=\nu_{p}^{(1)}}}{\left.\frac{d}{d z} R_{1}(z)\right|_{z=\nu_{p}^{(1)}}}\right)^{-1} .
$$

If $\nu_{p}^{(1)}=\xi_{r}$, then

$$
\begin{gathered}
(-1)^{r} R_{0}\left(\nu_{p}^{(1)}\right)=R_{0}\left(\xi_{r}\right)(-1)^{r}<0 \\
\left.(-1)^{r} \frac{d}{d z}\left(R_{1}(z) R_{2}(z)\right)\right|_{z=\nu_{p}^{(1)}}=\left.(-1)^{r} \frac{d}{d z}\left(R_{1}(z) R_{2}(z)\right)\right|_{z=\xi_{r}}>0, \\
\left.(-1)^{p} \frac{d R_{1}(z)}{d z}\right|_{z=\nu_{p}^{(1)}}>0,
\end{gathered}
$$

and, consequently,

$$
(-1)^{p-1} \tilde{X}_{1}\left(\nu_{p}^{(1)}\right)>0 .
$$

Therefore, the zeros $\left\{\chi_{k}^{(1)}\right\}_{k=2}^{n_{1}+1}$ of the polynomial $\tilde{X}_{1}(z)$ interlace with $\left\{\nu_{k}^{(1)}\right\}_{k=1}^{n_{1}}$ as follows:

$$
0<\nu_{1}^{(1)}<\chi_{2}^{(1)}<\nu_{2}^{(1)}<\cdots<\chi_{n_{1}}^{(1)}<\nu_{n_{1}}^{(1)}<\chi_{n_{1}+1}^{(1)} .
$$

Now we construct the polynomial

$$
X_{1}(z):=\prod_{k=2}^{n_{1}}\left(1-\frac{z}{\chi_{k}^{(1)}}\right)
$$

Due to $(3.9)$ the ratio $-\frac{R_{1}(z)}{z m_{1} X_{1}(z)}$ is an $S$-function and

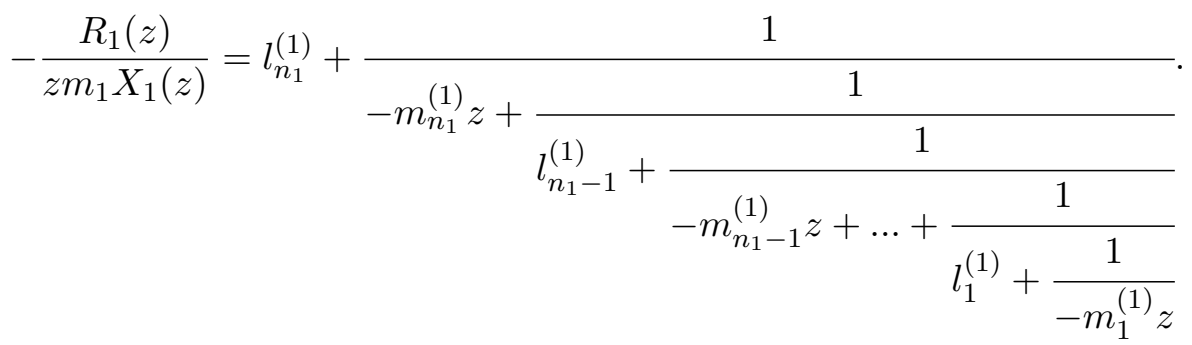

with $l_{k}^{(1)}>0, m_{k}^{(1)}>0$. 
Analogously to (3.6) we obtain

$$
\tilde{X}_{2}\left(\nu_{p}^{(2)}\right)=\frac{\left(m_{1}+m_{2}\right) \prod_{k=2}^{n}\left(1-\frac{\nu_{p}^{(2)}}{\mu_{k}}\right)}{m_{2} \prod_{k=1}^{n_{1}}\left(1-\frac{\nu_{p}^{(2)}}{\nu_{k}^{(1)}}\right)} .
$$

Denote by $\nu_{0}^{(2)}=0$, and set

$$
\tilde{X}_{2}\left(\nu_{0}^{(2)}\right)=1
$$

Then for $\tilde{X}_{2}(z)$ we have the Lagrange interpolating polynomial

$$
\tilde{X}_{2}(z)=\sum_{p=0}^{n_{2}-1} \tilde{X}_{2}\left(\nu_{p}^{(2)}\right) \prod_{i \neq p, i=0}^{n_{2}-1} \frac{z-\nu_{i}^{(2)}}{\nu_{p}^{(2)}-\nu_{i}^{(2)}}
$$

Similarly to (3.8) we arrive at

$$
(-1)^{p-1} \tilde{X}_{2}\left(\nu_{p}^{(2)}\right)>0
$$

The zeros $\left\{\chi_{k}^{(2)}\right\}_{k=2}^{n_{2}}$ of the polynomial $\tilde{X}_{2}(z)$ interlace with $\left\{\nu_{k}^{(2)}\right\}_{k=1}^{n_{2}}$ as follows:

$$
0<\nu_{1}^{(2)}<\chi_{2}^{(2)}<\nu_{2}^{(2)}<\ldots<\chi_{n_{2}}^{(2)}<\nu_{n_{2}}^{(2)}
$$

It follows from (3.9) and (3.11) that $\frac{\tilde{X}_{j}}{R_{j}}$ is an $S$-function for $j=1$ and $j=2$. Therefore,

$$
\left(\left(\frac{\tilde{X}_{1}}{R_{1}}\right)^{-1}+\left(\frac{\tilde{X}_{2}}{R_{2}}\right)^{-1}\right)^{-1}
$$

is also an $S$-function. This means that there is exactly one zero of $\tilde{X}_{1} \tilde{X}_{2}$ in the interval $\left(\mu_{n}, \infty\right)$. According to (3.11) this zero is $\chi_{n_{1}+1}^{(1)}=\nu_{n_{2}}^{(2)}$ and therefore $\nu_{n_{2}}^{(2)}>\mu_{n}$. Then due to (3.1) we arrive at $\nu_{n_{2}}^{(2)}>\mu_{n}>\chi_{n_{2}}^{(2)}$.

Due to (3.11) and the inequality $\nu_{n_{2}}^{(2)}>\chi_{n_{2}}^{(2)}$, we conclude that

$$
-\frac{R_{2}(z)}{z m_{2} \tilde{X}_{2}(z)}\left(1-\frac{z}{\nu_{n_{2}}^{(2)}}\right)
$$


is an $S$-function and

$$
\begin{aligned}
& -\frac{R_{2}(z)}{z m_{2} \tilde{X}_{2}(z)}\left(1-\frac{z}{\nu_{n_{2}}^{(2)}}\right)= \\
& =l_{n_{2}}^{(2)}+\frac{1}{-m_{n_{2}}^{(2)} z+\frac{1}{l_{n_{2}-1}^{(2)}+\frac{1}{-m_{n_{2}-1}^{(2)} z+\cdots+\frac{1}{l_{1}^{(2)}+\frac{1}{-m_{1}^{(2)} z}}}} .}
\end{aligned}
$$

where $l_{k}^{(2)}>0$ and $m_{k}^{(2)}>0$.

We identify the coefficients $m_{k}^{(2)}$ with the masses on the right part of the string and the coefficients $l_{k}^{(2)}$ with the subintervals of it.

Thus, we have found all the masses and the subintervals (except of $l_{0}^{(j)}$ ) of the left $(j=1)$ and of the right $(j=2)$ part of the string.

Now we need to prove that the spectrum of problem (2.2)-(2.5) generated by the obtained masses and subintervals coincides with $\left\{\mu_{k}\right\}_{k=1}^{n}$, where $\mu_{1}:=0$.

Let $Q_{2 n_{j}}^{(j)}(z)$ be the characteristic polynomial of Neumann-Dirichlet problem (2.11)-(2.13) generated by the obtained masses $\left\{m_{k}\right\}_{k=1}^{n}$ and subintervals $\left\{l_{k}\right\}_{k=1}^{n}$ (the values $l_{0}^{(j)}$ are arbitrary), let $Q_{2 n_{j}-1}^{(j)}(z)$ be the characteristic polynomial of Neumann-Neumann problem (2.11), (2.14), (2.15). Then (2.16) is valid. Comparing (2.16) where $j=1$ with (3.12), we conclude that

$$
Q_{2 n_{1}}^{(1)}(z)=T_{1} R_{1}(z), \quad Q_{2 n_{1}-1}^{(1)}(z)=-T_{1} m_{1} z X_{1}(z)
$$

where $T_{1}$ is a nonzero constant.

Comparing (2.16) where $j=2$ with (3.12), we arrive at

$$
Q_{2 n_{2}}^{(2)}(z)=T_{2} R_{2}(z)\left(1-\frac{z}{\nu_{n_{2}}^{(2)}}\right), \quad Q_{2 n_{2}-1}^{(2)}(z)=-T_{2} z m_{2} \tilde{X}_{2}(z) .
$$

Using (3.13)-(3.14) we obtain

$$
\begin{aligned}
& Q_{2 n_{1}}^{(1)}(z) Q_{2 n_{2}-1}^{(2)}(z)+Q_{2 n_{2}}^{(2)}(z) Q_{2 n_{1}-1}^{(1)}(z)= \\
& \quad=-T_{1} T_{2} z\left(m_{2} R_{1}(z) \tilde{X}_{2}(z)+m_{1} R_{2}(z) X_{1}(z)\left(1-\frac{z}{\nu_{n_{2}}^{(2)}}\right)\right)= \\
& =-T_{1} T_{2} z R_{0}(z)
\end{aligned}
$$


Thus, the spectrum of problem (2.2)-(2.5) generated by obtained masses and subintervals is $\{0\} \cup\left\{\mu_{k}\right\}_{k=2}^{n}$.

Let us prove now that the solution of the inverse problem is unique. Suppose there exists a collection

$$
\left\{\left\{\tilde{l}_{k}^{(i)}\right\}_{k=1}^{n_{j}},\left\{\tilde{m}_{k}^{(i)}\right\}_{k=1}^{n_{j}} \text { for } j=1 \text { and } j=2\right\}
$$

which does not coincide with the obtained collection

$$
\left\{\left\{l_{k}^{(i)}\right\}_{k=1}^{n_{j}},\left\{m_{k}^{(i)}\right\}_{k=1}^{n_{j}} \text { for } j=1 \text { and } j=2\right\}
$$

which generates problem (2.2)-(2.5) with the spectrum $\{0\} \cup\left\{\mu_{k}\right\}_{k=2}^{n}$, problem (2.11)-(2.13) with $j=1$ whose spectrum is $\left\{\nu_{k}^{(1)}\right\}_{k=1}^{n_{1}}$ and problem (2.11)(2.13) with $j=2$ for which $\left\{\nu_{k}^{(2)}\right\}_{k=1}^{n_{2}-1}$ are eigenvalues. Then

$$
\begin{aligned}
\phi(z) & =-T_{1} T_{2} z R_{0}(z)= \\
& =T_{1} R_{1}(z) \tilde{Q}_{2 n_{2}-1}^{(2)}(z)+T_{2} R_{2}(z) \tilde{Q}_{2 n_{1}-1}^{(1)}(z)\left(1-\frac{z}{\tilde{\nu}_{2 n_{2}}^{(2)}}\right),
\end{aligned}
$$

where $\tilde{Q}_{2 n_{1}-1}^{(1)}$ and $\tilde{Q}_{2 n_{2}-1}^{(2)}$ are the characteristic polynomials of problem (2.11), (2.14), (2.15) with $j=1$ and $j=2$, respectively, generated by the sets

$$
\left\{\left\{\tilde{l}_{k}^{(i)}\right\}_{k=1}^{n_{j}},\left\{\tilde{m}_{k}^{(i)}\right\}_{k=1}^{n_{j}} \text { for } j=1 \text { and } j=2\right\} .
$$

Subtracting (3.16) from (3.15) and using (3.13) and (3.14) we obtain

$$
\frac{T_{1} R_{1}(z)}{T_{2} R_{2}(z)}=-\frac{\tilde{Q}_{2 n_{1}-1}^{(1)}(z)\left(1-\frac{z}{\tilde{\nu}_{2 n_{2}}^{(2)}}\right)-Q_{2 n_{1}-1}^{(1)}(z)\left(1-\frac{z}{\nu_{2 n_{2}}^{(2)}}\right)}{\tilde{Q}_{2 n_{2}}^{(2)}(z)-Q_{2 n_{2}}^{(2)}(z)},
$$

and then $T_{1} R_{1}(0)=0$ which is false because $T_{1} \neq 0$ and $R_{1}(0)=1$.

\section{REFERENCES}

[1] O. Boyko, V. Pivovarchik. Inverse problem for Stieltjes string damped at one end. Methods Funct. Anal. Topology, 14(1):10-19, 2008.

[2] O. Boyko, V. Pivovarchik. Inverse spectral problem for a star graph of stieltjes strings. Methods Funct. Anal. Topology, 14(2):159-167, 2008.

[3] O. Boyko, V. Pivovarchik. The inverse three-spectral problem for a Stieltjes string and the inverse problem with one-dimensional damping. Inverse Problems, 24(1):13, 2008.

[4] W. Cauer. Die Verwirklichung von Wechselstromwiderständen vorgeschriebener Frequenzabhängingkeit. Arch. Elektrotech, 17(4):355-388, 1926.

[5] T. C. Fry. The use of continued fractions in the design of electrical networks. Bull. Am. Math. Soc, 35(153), 1929.

[6] F. R. Gantmakher, M. G. Krein. Oscillating matrices and kernels and vibrations of mechanical systems. AMS Chelsea Publishing, Providence, RI, 2002.

[7] J. Genin, J. S. Maybee. Mechanical vibration trees. J. Math. Anal. Appl., 45:746-763, 1974. 
[8] G. Gladwell. Inverse problems in vibration, volume 119 of Solid Mechanics and its Applications. Kluwer Academic Publishers, Dordrecht, 2004.

[9] G. Gladwell, A. Morassi. Dynamical inverse problems: theory and applications. CISM Courses and Lectures 529, pages 1-29, 2011.

[10] E. A. Guillemin. Synthesis of passive networks. Theory and methods appropriate to the realization and approximation problems. John Wiley and Sons, Inc., New York, 1958.

[11] I. S. Kac, M. G. Krein. $R$-functions - analytic functions mapping the upper half-plane into itself. Amer. Math. Transl. (2), 103(2):1-18, 1974.

[12] M. G. Krein. On some new problems of the theory of vibrations of sturm systems. Prikladnaya matematika i mekhanika, 16(5):555-568, 1952 (in russian).

[13] V. A. Marchenko. Introduction to the theory of inverse problems of spectral analysis. Acta, Kharkov, 2005 (in russian).

[14] M. Möller, V. Pivovarchik. Spectral theory of operator pencils, Hermite-Biehler functions, and their applications, volume 246 of Operator Theory: Advances and Applications. Birkhäuser/Springer, Cham, 2015.

[15] V. Pivovarchik. Existence of a tree of Stieltjes strings corresponding to two given spectra. J. Phys. A, 42(37):16, 2009.

[16] V. Pivovarchik, N. Rozhenko, C. Tretter. Dirichlet-Neumann inverse spectral problem for a star graph of Stieltjes strings. Linear Algebra Appl., 439(8):2263-2292, 2013.

[17] K. Veselić. On linear vibrational systems with one-dimensional damping. Appl. Anal., 29(1-2):1-18, 1988.

Received: October 10, 2018, accepted: May 5, 2019.

Anastasia Dudko

South Ukrainian National Pedagogical University named after K.D. Ushynsky

Email: nastysha00301@gmail.com

Vyacheslav Pivovarchik

South Ukrainian National Pedagogical University named after K.D. Ushynsky

Email: vpivovarchik@gmail.com

ORCID: orcid.org/0000-0002-4649-2333 